\title{
Late Retroperitoneal Haematoma after Psoas Compartment Block for Total Hip Arthroplasty
}

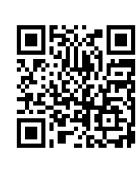

\author{
Calistri A*, Di Martino L, Gurzì MD, Ruggeri A, Fattorini F and Villani C \\ Department of Anatomical, Histological, Universityof Rome Sapienza, Italy
}

Received: January 27, 2018; Published: February 09, 2018

*Corresponding author: Alessandro Calistri, Orthopaedic Surgeon, Department of Anatomical, Histological, Forensic Medicine and Orthopedic Science, University of Rome Sapienza, Piazzale Aldo Moro 500136 Rome, Italy, Tel: 3299776300; Fax: 0649914846; Email: alessandro.calistri@uniroma1.it

\begin{abstract}
Objective: Post-operative anemia may be a compelling problem, sometimes sudden, of difficult diagnosis, that may be enhanced by underlying medical conditions, and that may influence therapeutic choices.

Case report: We present a case of sudden anemia (from 10.2 pt. to 7.3 pt. of HB in two days), after a total hip arthroplasty, performed under combined spinal and peripheral anesthesia, in a 70 years old woman who suffered from a coagulation disorder due to a rare genetic mutation (homozygosis for MTHFR C677T).

Conclusion: The anaemia was due to retroperitoneal hematoma with a pseudo aneurysm of the left lumbar artery, with active bleeding localized at L4, resolved by intervention of intravascular remobilization of the feeder artery of the pseudo aneurysm.
\end{abstract}

Keywords: Aneurysm; Replacement; Hip; Hematoma; Lumbar Plexus; Mthfrdeficiency

\section{Introduction}

The increasing demand for hip arthroplasty over the last decades has sparked the creation of new and innovative aesthetic techniques and analgesic pathways with the aim to support best possible outcomes in this elderly patient population. Despite some conflicting reports, a growing number of studies indicate that neuraxial anesthesia may prove beneficial to patients undergoing major joint replacement [1]. The poses compartment block has been described as analgesically potent as an epidural technique during hip surgery, but several possibilities of severe complications are reported, the main risk is intrathecal or intranasal application of cardio toxic doses of local anaesthetics but there are other more rare complications related to patient's clinical condition [2].

\section{Case Report}

We present a case of a retroperitoneal hematoma without lumbar neuropathy after psoas compartment block (PCB), in a 70 years old woman who underwent total hiparthroplastyon left side. Before surgery the anaesthetist performed an L2-L3 spinal block and after several attempts, without aspiration of blood, and then aL4-L5 PCB to ensure the postoperative analgesia. The patient had family history of cardiovascular disease, suffered from high blood pressure and diabetes; she had undergone bilateral saphenectomy at the age of 31 years, and she had an episode of phlebitis in July
2011, at this period diagnosis of homozygosis MTHFR C677T was made. This genetic disorder causes a severe deficiency of metilen-tetrahidrofolate-reductase and it is associated with raise of homocysteinemia and homocystinuria, low levels of folic acid, and high risk of thromboembolism [3]. Hence, the patient has been treated with low-molecular-weight heparin (LMWH) 6000 U.I. since July 2011.The patient suffered from a considerable weight loss $(35 \mathrm{Kg}$ ) in the year before hip arthroplasty with unexplained cause. The surgery was uneventful with the patient awake using standard monitoring. The intervention lasted 50minutes, with no significant blood loss from the poster lateral approach.

Furthermore, no sign of surgical wound bleeding was seen in the first day following surgery. At second postoperative day because of dropping of HGB value from 10.2 to $7.3 \mathrm{mg} / \mathrm{dl}$, the patient was treated with transfusion of two units of homologous blood, the HGB value raised to $8.8 \mathrm{mg} / \mathrm{dl}$. The 5 th days post intervention the patient lowered to $6.3 \mathrm{mg} / \mathrm{dl}$ and felt uncomfortable and complained pain around left iliac foss a without sensory-motor deficit. She was visited by the orthopaedic surgeon, who performed intervention, and, at that area, a large oedema was visible. The same day the patient undergone a CT scan with contrast, which evidenced a left retroperitoneal hematoma with a pseudo aneurysm of the left lumbar artery, with active bleeding localized at L4 and, the 
day after, she has undergone an intervention of intravascular remobilization of the feeder artery of the pseudo aneurysm (Figure 1)by the vascular surgery unit. Following, the patient was treated with three unit of homologous blood, stabilized (HGB value $=8.6$ $\mathrm{mg} / \mathrm{dl}$ ), and then discharged after four days with a rehabilitation program. The patient at six weeks was regularly followed up in outpatient ambulatory, she reported a full restore of her quality of life and experienced an uneventful rehabilitation course.

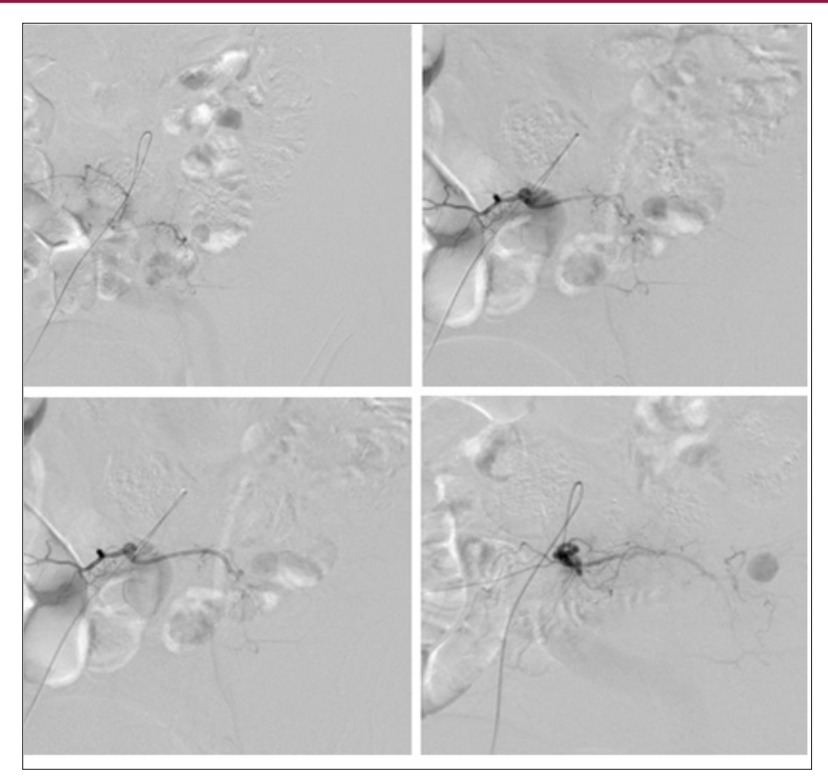

Figure 1: Remobilization of pseudo aneurysm's feeder artery.

\section{Discussion}

The use of peripheral nervous block has become common practice in major orthopedic surgical procedures and, as literature shows, it demonstrated good intraoperative and postoperative analgesia, better efficiency than parenteral opioids with less impact on the organism, early mobilization and reduction of the thrombi-embolic risks [4]. The posterior approach to the lumbar plexus is the most used, which results in a complete block of the principal nerves of the lumbar plexus [5-6]. Stevens et al showed a decrease of blood loss intraoperatively after lumbar plexus block and also a reduction of hemorrhage $48 \mathrm{~h}$ following surgery [7]. However, literature reports a failure rate for neurostimulation guided anesthesia for lumbar plexus localization around 5-7\% [8]. This type of local-regional anesthesia is not free of complications. Thus, without considering complications due to the insertion of the needle too deep (accidental puncture of the duodenum, or peritoneum, or lower pole of kidney, or ureter), it is rarely possible to have a spread of the anesthetic in the epidural space, with following convulsions caused by systemic rapid absorption of the anesthetic [9], or bleeding due to high vascularization of the area in which the lumbar plexus is located (lumbar arteries, ascending lumbar veins) [10-11].

Therefore, unrecognized aneurysms or other vascular lesions can facilitate this complication. The presence of a pseudo aneurysm of the left lumbar artery, the underlying hematologic disease, daily drug treatment [12] and, most probably, the repeated attempts of injection for anesthesia performed by resident doctors, are the causes that led to this complication. In conclusion, it is advisable to perform this type of procedure always with support of ultrasound and possibly with a specialist who has passed the learning curve. In view of the excellent results with now standardized anesthetic methods we believe the routine useof this procedure for patients undergoing a hip replacement isn't justified.

\section{Authors' contributions}

1) Substantial contributions to conception and design, or acquisition of data, or analysis and interpretation of data was by L.D.M. and A.R.; 2) Drafting the article or revising it critically for important intellectual content by F.F. and M.D.G., 3) Final approval of the version to be published was by A.C. and C.V.

\section{Acknowledgement}

We would like to thank Dr. Di MartinoC., Head Physician in Anaesthesia in private clinic "Bernardini" of Taranto, for contributing to the revision of the discussion of this manuscript.

\section{References}

1. Opperer M, Danninger T, Stundner O, Memtsoudis SG (2014) Perioperative outcomes and type of anesthesia in hip surgical patients: An evidence based review. World J Orthop 5(3): 336-343.

2. Capdevila X, Coimbra C, Choquet $O$ (2005) Approaches to the lumbar plexus: success, risks, and outcome. RegAnesth Pain Med 30(2): 150162.

3. Ueland PM, Hustad S, Schneede J, Refsum H, Vollset SE (2001) Biological and clinical implications of the MTHFR C677T polymorphism. Trends Pharmacol Sci 22(4): 195-201.

4. Capdevila X, Macaire P, Dadure C, Choquet O, Biboulet PH, et al. (2002) Continuous psoas compartment block for postoperative analgesia after total hiparthroplasty: New landmarks, technical guidelines, and clinical evaluation. Anesthanalg 94(6): 1606-1613.

5. De Visme V, Picart F, Le Jouan R, Legrand A, Savry C, Morin V (2000) Combined lumbar and sacral plexus block compared with plain bupivacaine spinal anesthesia for hip fractures in the elderly. Reg Anesth Pain Med 25(2): 158-162.

6. Farny J, Girard M, Drolet P (1994) Posterior approach to the lumbar plexus combined with a sciatic nerve block using lidocaine. Can J Anesth 41(6): 486-491.

7. Stevens RD, VanGessel E, Flory N, Fournier R, Gamulin Z (2000) Lumbar plexus block reduces pain and blood loss associated with total hip arthroplasty. Anesthesiology 93(1): 115-121.

8. De Visme V, Picart F, LeJouan R, Legrand A, Savry C, et al. (2000) Combined lumbar and sacral plexus block compared withplainbupivacaine spinal anesthesia for hip fractures in the elderly. RegAnesth Pain Med 25(2): 158-162.

9. Breslin DS, Martin G, Macleod DB, D'ercole F, Grant SA (2003) Central nervous system toxicity following the administration of levobupivacaine for lumbar plexus block: A report of two cases. Reg AnesthPainMed 28(2): 144-147.

10. Aveline C, Bonnet F (2004) Delayed retroperitoneal haematomaafter failed lumbar plexus block. Br J Anaesth 93(4): 589-591.

11. Weller RS, Gerancher JC, Crews JC, Wade KL (2003) Extensive retroperitoneal hematoma without neurologic deficit in two patients 
who underwent lumbar plexus block and were later anticoagulated. Anesthesiology 98(2): 581-585.

\section{(c) (i) This work is licensed under Creative} Submission Link: http://biomedres.us/submit-manuscript.php
12. Klein SM, D’Ercole F, Greengrass RA, Warner DS (1997) Enoxaparin associated with psoas hematoma and lumbar plexopathy after lumbar plexus block. Anesthesiology 87(6): 1576-1579.



